ICEEPSY 2021

$12^{\text {th }}$ International Conference on Education \& Educational Psychology

\title{
THE TEACHING AND LEARNING OF ENGLISH INDIRECT QUESTIONS: PERCEPTIONS OF CZECH NATIVE SPEAKERS
}

\author{
Vera Tauchmanova (a)* \\ *Corresponding author \\ (a) University of Hradec Kralove, Faculty of Education, Rokitanskeho 62, Hradec Kralove, Czech Republic, \\ vera.tauchmanova@uhk.cz
}

\begin{abstract}
This paper presents a case study which focused on the issue of teaching and learning English indirect questions from both learners' and teachers' points of view. The research was carried out during the 2020 21 academic year, and its objective was to identify possible ways of making the process of teaching and learning of English indirect questions in the Czech educational environment more effective. A qualitatively oriented study was carried out within the framework of the course called "Practical English and its Methodology" offered to pre-service teachers of the Faculty of Education of the University of Hradec Kralove (Czech Republic) majoring in teaching English at Czech elementary schools. 16 students participated where they explored learning and teaching materials and reflected on them. The findings revealed that the students realised that their linguistic and methodological competence should be improved and they were willing to find inspirations concerning possible ways of presenting and practising indirect questions in English classes. They highlighted some existing similarities between English and Czech indirect questions. Their awareness of these similarities can help improve their teaching techniques when teaching English indirect questions to Czech native speakers.
\end{abstract}

2672-8141 @ 2021 Published by European Publisher.

Keywords: Indirect questions, teaching and learning materials, positive transfer 


\section{Introduction}

The Faculty of Education of the University of Hradec Kralove (Czech Republic) offers numerous courses for pre-service and in-service teachers who will teach or who are already teaching at Czech primary and secondary schools. These pre- and in-service teachers are trained in all the subjects which are included in the primary and secondary school curricula issued by the Czech Ministry of Education.

One of the courses which is compulsory for pre-service teachers trained for teaching at elementary schools (i.e. lower primary schools) is the course called "Practical English and its Methodology". As indicated by its name, the objective of the course is not only to improve the students' practical English and all their language skills, but also to improve their abilities and skills of presenting linguistic issues to young learners aged $6-11$. The students enrol in the course with a minimum of intermediate level proficiency English. They are supposed to progress to upper-intermediate proficiency in English, and simultaneously acquire methodological skills and consider the best possible ways of presenting English systematically to their future learners. Within the framework of the course, our pre-service teachers are encouraged to be creative, to explore the target language and to discover how the language system works. It is believed that discovery activities can help improve creativity. As Harmer (1994) says: “...discovery activities are so valuable since by asking students to discover ways in which language is used, we help to raise awareness about the creative use of grammar - amongst other things" (p. 23). It can be extrapolated that the creativity resulting from discovery activities is not limited to just the creative use of grammar; this creativity can be then expected to energise the whole teaching process.

The instructors try their utmost to convince undergraduates of the truth of the following statement made by Ur (2009): "Learning more about language and about how language works is a useful, productive and interesting activity: increasing one's awareness - being more 'alive' to language - can bring considerable benefit, both personal and professional" (p. 5). That is why the students are referred to various linguistic materials from which they can learn more about the language system. The pre-service teachers in the Faculty of Education of the University of Hradec Kralove are also encouraged to reflect on available methodological findings and to generate possible ways how to present their linguistic knowledge to their learners.

This paper presents the findings of a case study that was carried out during the $2020-21$ academic year, and focused on the challenges of learning and teaching English indirect questions from both the learner's and the teacher's point of view. Due to the global Covid pandemic situation, the course in practical English and its methodology was conducted online using the MS Teams platform, which enabled active involvement of all the participants.

\section{Problem Statement}

The competence to interpret questions is important in both formal and informal texts. Therefore, learners of English should be made properly aware of the existing structures of English reported questions.

It is true that in everyday informal oral communication, we usually do not care so much about the perfect and correct ways of interpreting directly asked questions; potential misunderstandings can be sorted out immediately. However, in the process of training of foreign language teachers, we should make our 
trainees aware of the fact presented by Ur (2009) who states that "There are rules which govern how words have to be manipulated and organized so as to express the meaning: a competent speaker of the language will be able to apply these rules so as to convey his or her chosen meanings effectively and acceptably" ( $p$. 3). Currently, with the increasing impact of modern technologies enabling new ways of communication, there is a corresponding increase in how other people's and the media's questions are to be interpreted and expressed. To avoid misunderstandings (which could be crucial in some cases) and to be effective in our communication, we have to correctly apply the rules existing in the target language.

The issue of correct structuring of English indirect questions is neglected in teaching and learning materials. Non-native speakers are more or less expected to struggle with this issue, which Fitikides (2000) highlights "to help to correct the common mistakes to which foreign learners of English are liable" (p. 3). The author, whose list of the mistakes commonly made by foreign learners is "the result of observations made over a long period of time", draws attention to English indirect questions in Part 4 (Misplaced words) of the publication by emphasising the following fact (Fitikides, 2000): "In indirect questions, the subject comes first and then the verb" (p. 82). An incorrect indirect question is presented also in Part 1 (Misused forms) of the publication as an example of a wrong sequence of tenses: "Rachel asked me what I am doing" (Fitikides, 2000, p. 20).

Learners of English generally do not consider English indirect questions to be problematic from the communicative point of view. Before studying the recommended learning materials, the trainees participating in this study were asked about their opinions of and their experience with this issue. They could not recall any real problems they had had to cope with when dealing with indirect questions. However, these reactions unfortunately, resulted also from the fact that the students were actually not able to clarify what indirect questions actually are. The trainees were aware of the existence of this structure and of the fact that they had encountered the issue during their previous studies of English, but they really struggled with giving examples of English indirect questions and with making theoretical comments on these structures. Being given some examples of indirect questions, the pre-service teachers pointed to the changed word order, but they themselves felt that their linguistic and methodological competences should be improved.

\section{Research Questions}

Referring to the purpose of this study and reflecting on personal experience, the following research questions were formulated:

RQ1: What are the most problematic issues in the process of teaching and learning English indirect questions?

RQ2: How can the teaching of English indirect questions to Czech native speakers be improved?

These questions are obviously related to ways in which the issue of indirect questions is presented in teaching and learning materials available in the Czech Republic. A vast majority of these materials were published by publishing institutions located in English speaking countries, so they tackle the issue from native speakers' points of view, and although generally common mistakes made by non-native speakers of English may be dealt with, some explanations and clarifications may not be fully comprehensible for non- 
native speakers learning English. Moreover, these teaching and learning materials usually ignore the possibility of a positive transfer based on the assumption that there are at least some general and universal features which are typical of indirect questions not only in English but in other languages. The issue of the positive transfer is quite important in this research since the researching pre-service teachers will also teach the Czech language. Their enhanced awareness of the structural phenomenon existing in both the languages would be beneficial in their future professional teaching career since such an awareness would enable a more effective teaching of both the languages.

\section{Purpose of the Study}

The main purpose of the study is to find possible ways of making the process of teaching and learning of English indirect questions in the Czech educational environment as effective as possible. This structural issue is presented in numerous English teaching materials, its presentations slightly vary and sometimes they can be oversimplified or not completely clear. It is then up to teachers to present the issue in the way which is the most convenient for their learners to grasp. It is believed that the effectiveness of teaching English grammatical issues improves if "conveniently chosen examples referring to the students' already acquired knowledge are used, since the students are effectively motivated to constructively use their already existing linguistic abilities and skills“ (Ondrakova et al., 2019, p. 144). Foreign language teachers should always keep Ondrakova and Tauchmanova's (2020) contention that "Knowledge and skills acquired during the process of acquisition and learning of their mother tongue are consciously and unconsciously transferred by learners into the process of learning their first foreign language" (p. 167). This fact cannot be generally ignored when Czech native speakers are being trained in teaching English in the Czech educational environment. This study highlighted this aspect since the students involved in the research are also being trained to teach the Czech language as their learners' mother tongue.

\section{Research Methods}

The research was qualitatively oriented and was carried out within the framework of the course called "Practical English and its Methodology". The research was kept largely formative in nature where the participants were asked to undertake an in-depth exploration of the recommended materials related to the study of English indirect questions and simultaneously encouraged to seek out other learning texts and materials. The focus was placed on comparative analysis of these materials from both the linguistic and methodological point of view. The students were encouraged to also undertake a comparative analysis of English and Czech structures of indirect questions, and to find similarities and dissimilarities between these structures. The comparative analysis was first made by each student individually, then the students discussed the results of their individual analyses and the findings made by their peers. The online discussions among the students were monitored and chaired by the instructor.

The comparative analysis carried out both individually and as group work not only trained the students in their research work, but also in defending their opinions, in learning from their colleagues' opinions and from their instructor's experience. They were also exposed to learning from their own and 
their peers' mistakes. The knowledge and skills gained through this qualitative research would benefit the students' future professional teaching career.

\section{Findings}

The following part of the paper presents the findings of the research. The course Practical English and its Methodology was taken by sixteen students (all of them were females) who were pre-service teachers being trained to teach at elementary schools (lower primary schools) in the Czech Republic. English would be one of compulsory school subjects taught by these trainees.

The students were asked to reflect on the issues related to English indirect questions. They were asked to explore presentations and explanations given in various teaching and learning materials and they were supposed to refer to their personal experience with working with the texts and to think about potential ways of adjusting the texts to render them more comprehensible for Czech native speakers learning English. As mentioned above, the students involved in the research would teach young learners aged 6 to 11 , so the issue of English indirect questions was, on purpose, not approached too "academically"; hence, some more problematic phenomena were avoided.

During the research, it was revealed that Czech native speakers are not fully aware of possibilities of using their previously acquired linguistic knowledge and skills when studying and using English reported questions in practice

\subsection{Reflections on teaching and learning materials}

The basic learning material used in the course within the framework in which the research was carried out was the New English File Upper-intermediate textbook. The issue of indirect questions occurs in the opening 1A Unit of the textbook (as a kind of revision). The rules applied to the issue of indirect questions are just summarised on page 132 of the Student's Book (Oxenden \& Latham-Koenig, 2008). At the initial stage of the research, the students were referred to this summary, and they were asked to make comments on the clarity of the following text presented in the textbook: "Use indirect questions when you want to ask a question in a more polite way (Could you tell me where she lives?). In indirect questions the order is subject + verb (Can you tell me where it is?). Don't use do / did in the second part of the question (Do you know where he lives?). You can use if or whether after Can you tell me, Do you know, etc., e.g. Can you tell me if / whether he is at home?."

At first, the students said that the text was more or less comprehensible. However, having been encouraged by the instructor to explore the meaning of each sentence in detail, they started to wonder about the clarity of the text and they asked questions like: "What is the second part of the question?", "Is this second part a real question?", "What is the first part of the question?". The above presented explanation of using 'if" or 'whether' was more or less confusing since it provoked the following questions: "Does that 'can' mean that you needn't to use the words?", "Are there any other situations in which you use 'if' or "whether'?". At this point, the students were referred to the way in which indirect questions were presented in the immediately preceding level of the textbook, i.e. in New English File Intermediate Student's Book. They were not very happy about the following presentation since they found it even less helpful: "When 
you report a question, the tenses change as in a reported statement. When a question begins with a verb (not a question word), add if or whether. You also have to change the word order to subject + verb, and not use do / did." (Oxenden \& Latham-Koenig, 2006, p. 140). The students' comments on this presentation were: "Why is that change of tenses ignored in the textbook for more advanced students?", "Now we know when to use 'if' or 'whether' but it is not clear where to add these words.", "I more or less understand that 'do' is not used, but the real explanation is still missing".

After the introductory discussions, the students were referred to other learning and teaching materials which they were asked to explore and to generate the best possible ways of how English indirect questions can be best presented to Czech native speakers. Below, is a summary of comments, reflections and recommendation which resulted from the students' individual research and from the following discussions within the group.

The students felt that it is important to mention the fact that indirect questions are "included in the topic of indirect speech" and that is important to start with clarifications of structures generally used in indirect speech. They considered presentations given in Carter and McCarthy (2006) to be helpful:

An indirect report consists of a reporting clause, plus a reported clause which is more fully integrated as the object of the reporting verb and not usually separated by punctuation. The reported clause has a form which reflects the speech act of the original utterance. (p. 804)

The definition of an indirect report may look and sound too "academic", but teachers can adjust the wording to make it comprehensible to their learners. However, one essential comment is missing - a clarifying comment on the word "plus", i.e. a clarification of the way in which the reporting clause and the reported clause are connected. Carter and McCarthy (2006) refer to this issue in the following way: "Indirect interrogative clause refers to the use of wh-clause, a clause with if / whether" (p. 907). Discussing this sentence, the students were referred to the same authors explaining this phenomenon in other parts of their publication: "Polar interrogative clauses typically function to ask questions to which the answer is yes or no (yes-no questions), or questions with $x$ or $y$ (alternative questions), where the respondent must choose between alternatives" (Carter \& McCarthy, 2006, p. 534); "When a polar interrogative is reported indirectly, if or whether is used. Whether tends to be more formal. The reported clause has subject - verb x word order" (Carter \& McCarthy, 2006, p. 539). Discussing these explanations with the instructor's support and reference to Czech indirect questions, the students came up with these summarising presentations: "If there is a question word or a question phrase at the beginning of a direct question, the transformed indirect question starts with this question word or phrase, then the subject is used, and the verb and the rest of the clause follow. If a direct question starts with a verb, the transformed indirect question is introduced by "if" or "whether", then the subject is used, and the verb and the rest of the clause follow". The students got rather surprised by the fact that the same procedures and "rules" are applied in case of Czech indirect questions, and that there are even Czech equivalents for English words "if" (= "jestli" in Czech) and "whether" (= "zda" in Czech). A majority of the students admitted that not until that moment had they thought about a possibility of explaining any English structures by comparing them with equivalent Czech structures. 
Discussing other features typical of indirect questions, the following clarification was considered by the students to be comprehensible and helpful: "When someone's words are reported indirectly, pronouns, tenses, clause types, etc. change to reflect the situations of the current report in relation to the original moment of speaking of the words reported. She said, "What shall I do?" would typically be transformed into an indirect report as: She asked what she should do.” (Swan \& Walter, 2015, p. 805) The authors clarify the changes in the following way: "I has now become she, as the speaker is reporting the words of a female third person. Shall has become should to reflect the time lapse since the words were uttered. The interrogative clause has become declarative as the clause is now an indirect report and is no longer a direct question. Said has become asked as a question is being reported." Being referred to the clarifications above and with the instructor's support, the students came up with the following simplified clarification: "The reported (indirect) question becomes a 'normal' declarative clause (it is no longer a direct question) - the subject precedes the verb form, and in positive clauses in present simple and past simple no 'do / does / did ' are used. Reporting someone else's questions quite often requires other logical changes (especially in using personal and possessive pronouns)" (Swan \& Walter, 2015, p. 805).

Referring to general features of indirect questions, the students indicated their preference for Fuchs and Bonner's (2003) text: Indirect questions are a kind of embedded question - one that is included in another sentence. If the embedded question is in a question, use a question mark at the end of the sentence: Do you know who our waiter is? We often use embedded questions to a) express something we do not know: I wonder why he did not tip the waiter., b) ask politely for information: Can you tell me if the tip is included?. With strangers or in a formal situation, an embedded question is considered more polite than a direct question. At this point, it seems interesting to mention the fact that the students developed a discussion on the issue of incorrect usage of question marks / full stops at the end of Czech structures in which indirect questions are used. The same kind of mistakes occur both in Czech and in English, e.g. *I would like to know who is coming tomorrow? *Can you tell me who is coming tomorrow. The students agreed that one of the most universal explanations of the structure of English indirect questions was presented by Mann and Taylore-Knowles (2008): "We do not use question word order in the second part of the sentence" (p. 119). However, another wording used by the same authors can be rather confusing: "Some indirect questions, which begin with a question word, need a question mark at the end (Could you tell me where the library is?)" (Mann \& Taylore-Knowles, 2008, p. 119). It is not clear what is meant by the term "question word" (especially in the given example); the word "some" can indicate other unclear contexts. Summarising the issue of using question marks / full stops, the students came up with a re-wording of one of the sentences by Fuchs and Bonner presented above. This re-wording also works for Czech structures: "If an indirect question is introduced by a question, there is a question mark at the end of the whole structure." This reality made the participants even more aware of the existence of the positive language transfer, and the possibility of using this phenomenon in the process of teaching English to Czech native speakers.

\subsection{Reflections on linguistic and methodological explorations and already acquired skills}

After summarising discussions, the students took a short test in which they were supposed to change the direct questions below into indirect ones. The test was designed to reflect the pre-service teachers' 
future teaching career (teaching young learners), so it excluded more problematic tasks (e.g. changes in deictic expressions, transforming indirect questions into direct ones, etc.):

Why did she leave without saying goodbye? - I wonder

When does the college end for the summer? - I am not sure

Can we bring guests to the party? - Do you have any idea

What types of batteries does this need? - Do you know $?$

Where are the toilets? - Can you tell me $?$

How many people have you invited? - I can't remember

Why are you sitting here? - I would like to know

Eight students managed to change all of these seven direct questions into correct indirect ones. Not surprisingly, the most problematic was the transformation of the direct questions which included the "do" operator forms. There were two kinds of mistakes made by eight students: No structural changes were applied; the structure of a direct question was used (e.g. "I am not sure *when does college end for the summer." or "Do you know *what type of batteries does this need?") or the word order was correctly changed but the operator was still used (e.g. the direct question "Why did she leave without saying goodbye?" was transformed into "I wonder *why she did leave without saying goodbye.")

It was interesting to find out that the students did not make mistakes when transforming direct questions in which modal verbs were used (e.g. the direct question "Can we bring guests to the party?" was correctly transformed by all the 16 students into "Do you have any idea if we can bring guests to the party?" even though there was a question mark at the end of the structure). Discussing this issue, the students themselves came up with the idea that in their future teaching career, questions in which modal verbs are used will be given as initial examples of transformations of direct questions into indirect ones. The students were more or less surprised when the instructor drew their attention to the fact that this "easy" aspect could be explained by positive transfer from the Czech language since the structuring of English and Czech indirect questions in which modal verbs are used is completely the same.

Direct questions in which auxiliary verbs are used for expressing the desired tense and / or for expressing the desired voice seem to be more problematic than questions containing modal verbs as operators - an incorrect word order occurred in some cases (e.g. "I would like to know * why are you sitting here." "I can't remember *how many people have you invited."). Referring to the above mentioned "ease" of modal verb structures, the students gradually realised the potential of the positive transfer even in this case - if a Czech verb form includes an auxiliary verb (which is less frequent than in English), the structuring of English and Czech indirect questions is completely the same as well.

Discussing the students' reflections, it is heartening to note that the students were willing to find inspirations concerning possible ways of presenting and practising indirect questions in English classes. They themselves recommended a practical exercise "Can you remember what they asked?" which was inspired by Penny Ur's “Can you remember what they said?" (Ur, 2013, p. 81). This type of activity is quite challenging - not only does it practise the structures of indirect questions, but it also improves memorizing skills. At this point, it seems convenient to refer also to Heinrichova (2020), who suggests that "students 
should discuss the same situation from different perspectives, i.e. they should practice not only grammatical but also intellectual knowledge" (p. 79).

During the summarising discussions, the students compared the advantages and disadvantages of the natural language acquisition and controlled learning. The particpants' opinion was that controlled learning is more effective if it comes to the topic of English indirect questions since quite a high level of linguistic competence is necessary. The effectiveness of controlled learning definitely depends on the instructional methods which is the reason the students were referred to the following idea: "The results of controlled teaching depend on the level of a particular learner's active involvement into the studies of the given foreign language" (Tauchmanova et al., 2017, p. 107). In connection with controlled learning, the participants appreciated materials in which the presentations helped the learners notice important information about the presented grammar issues. As an example, they mentioned Fuchs and Bonner's Chart Checks in which the learners are expected to circle $\mathrm{T}$ (True) or $\mathrm{F}$ (False) in case of the following statements: "You can leave out if or whether in indirect yes/no questions. You do not use do to from indirect yes/no questions. An indirect question always ends in a question mark. You do not use do to from indirect $w h$ questions" (Fuchs \& Bonner, 2003, p. 326).

Finalising the discussions, the instructor asked the participants about potential reasons for the fact that, at the outset of the research into English indirect questions, they could not remember serious problems they had had with this grammatical phenomenon. It was difficult for the students to answer this question, so they were referred to Swan and Walter's (2015) opinion concerning teaching the issue of indirect speech: "Exercises in books are useful for practising the grammar of indirect speech, but they are necessarily rather artificial. In real life, when we report what people say, we re-express their meaning, but we don't necessarily keep very close to the original words. ... Indirect speech in English is mostly a matter of common sense saying what is natural in the situation" (p. 223). Moreover, it is possible and quite usual to report "directly" as explained by Carter and McCarthy (2006): A direct report consists of a reporting clause and a reported clause. The reporting clause contains a verb indicating speech, such as ask, demand, say, shout, tell. The reported clause represents or attempts to recreate the exact words someone used, as they occurred at the moment of speaking, with the same pronouns, tenses, clause types, etc. which the original speaker used. That "direct reporting" is sometimes intentionally advised even by materials presenting correct grammar structures, e.g. by Oxford Living Grammar upper-intermediate: "Remember that in conversation we can just repeat what someone actually said: At about ten o'clock last night Katie said to me, 'Listen, I'm tired. I'm going home" (Paterson, 2012, p. 68). When we also consider the fact that it is possible to combine direct and indirect reporting of questions, which can result in acceptance of some grammatically incorrect structures, then the students' self-confidence about English indirect questions can be explained. And in mentioning those acceptable incorrect structures, Carter and McCarthy's (2006) explanation can be referred to: "When a wh-interrogative is reported indirectly, the word order in the reported clause is normally subject - verb - x, not interrogative. However, in informal speech, interrogative word order is sometimes used: She wanted to know why didn't I go too" (p. 540). 


\section{Conclusion}

Reported questions are a common phenomenon occurring in English informal and formal speech (both spoken and written). That is why it is necessary to improve ways of presenting this to learners of English as a foreign language and to reflect on their previously acquired linguistic knowledge and skills. The students were quite surprised about the fact that the research into the effectiveness of teaching was enjoyable for them. Similar findings had been already made by Tauchmanova (2020) who said that "Our research also showed that deeper explorations of grammar issues and their presentations are welcomed by students majoring in teaching foreign languages" (p. 218). The pre-service teachers who participated in this study agreed with Parrot (2005), who says that this kind of research can help them "to evaluate the effect their teaching has on their learners' awareness, understanding and speaking or writing” (p. 457). It was quite surprising for the participants to identify existing similarities between English and Czech indirect questions and to reveal the existence of the positive language transfer. It is expected that this awareness will be transferred during teaching to their future learners in getting them to fall back on their knowledge of Czech structures while being taught similar English structures; consequently becoming more competent in both the languages.

\section{Acknowledgments}

The research and the publication of the text was financially supported by a grant of the Specific research 2020 of the Faculty of Education of the University of Hradec Kralove (No. 2123/01360/1210).

\section{References}

Carter, R., \& McCarthy, M. (2006). Cambridge Grammar of English. Cambridge University Press.

Fitikides, T. J. (2000). Common Mistakes in English. Pearson Education Limited.

Fuchs, M., \& Bonner, M. (2003). Grammar Express. Pearson Education Limited.

Harmer, J. (1994). The Practice of English Language Teaching. Longman Group UK Limited.

Heinrichova, N. (2020). Generational novel in Times of Fading light by Eugen Ruge in FLT. European Proceedings of International Conference on Education \& Educational Psychology, 1, 72-79. https://doi.org/10.15405/epiceepsy.20111.7

Mann, M., \& Taylore-Knowles, S. (2008). Destination B2: Grammar and Vocabulary. Macmillan Publishers Limited.

Ondrakova, J., \& Tauchmanova, V. (2020). Comparison of The Verbal Category of Tense in German and English. European Proceedings of International Conference on Education \& Educational Psychology, 1, 166-174. https://doi.org/10.15405/epiceepsy.20111.15

Ondrakova, J., Tauchmanova V., \& Goebelova, Z. (2019). Anglická, česká a némecká slovesa ve vzájemném srovnání [English, Czech and German verbs in their Mutual Comparison]. Pavel Mervart.

Oxenden, C., \& Latham-Koenig, C. (2006). New English File Intermediate Student's Book. Oxford University Press.

Oxenden, C., \& Latham-Koenig, C. (2008). New English File Upper-intermediate Student's Book. Oxford University Press.

Parrot, M. (2015). Grammar for English Language Teachers. Cambridge University Press.

Paterson, K. (2012). Oxford Living Grammar upper-intermediate. Oxford University Press.

Swan, M., \& Walter, C. (2015). Oxford English Grammar Course. Oxford University Press. 
Tauchmanova, V., Ondrakova, J., Kucera, V., Tauchmanova, V. Jr., Vokrinkova, J., \& Vranova, M. (2017). (Ne)výhody zkušeností s prvním cizím jazykem při studiu dalšich cizich jazyků [(Dis)Advantages of Experience with Learning the First Foreign Language in the Process of Learning Other Foreign Languages]. Gaudeamus.

Tauchmanova, V. (2020). English Reported Speech Taught to Czech Native Speakers. European Proceedings of International Conference on Education \& Educational Psychology, 1, 210 - 219. https://doi.org/10.15405/epiceepsy.20111.19

Ur, P. (2009). A Course in Language Teaching. Cambridge University Press.

Ur, P. (2013). Grammar Practice Activities. Cambridge University Press. 